\title{
ENGENHARIA DE MANUTENÇÃO APLICADA À DOCAGEM DE EMBARCAÇÕES
}

\section{ARTIGO DE REVISÃO}

BOUÇAS, Isabela de Almeida ${ }^{1}$

BOUÇAS, Isabela de Almeida. Engenharia de manutenção aplicada à docagem de embarcações. Revista Científica Multidisciplinar Núcleo do Conhecimento. Ano 05, Ed. 06, Vol. 09, pp. 34-42. Junho de 2020. ISSN: 2448-0959, Link de acesso: https://www.nucleodoconhecimento.com.br/engenharia-de-

\section{producao/docagem-de-embarcacoes}

\section{RESUMO}

O processo de manutenção de máquinas, equipamentos e estruturas que compõe uma embarcação é denominado docagem. Todos os navios devem ser submetidos a revisões e manutenções periódicas após certo tempo em operação, independentemente de sua função ou local de navegação. Esse é um processo complexo, que envolve sistemas multidisciplinares e interligados. A docagem exige a inoperância da embarcação durante o período de manutenção e reparo, e tem como finalidade identificar a existência de falhas e possíveis falhas, para corrigi-las ou evitálas. O objetivo do presente artigo é analisar o procedimento de manutenção e reparo de embarcações, indicando as suas principais características e desafios, e assim mostrar a relevância da docagem para o engenheiro de manutenção. Dessa forma, a partir da revisão bibliográfica de diversos autores, o artigo apresenta, inicialmente, uma breve descrição da evolução histórica da manutenção, e introduz os conceitos

${ }^{1}$ Pós-graduação em Engenharia e Gerenciamento de Manutenção - Universidade Cândido Mendes, pós-graduação em Engenharia de Produção e Gerenciamento de Projetos - Universidade Cândido Mendes, graduação em Engenharia Naval e Oceânica - Universidade Federal do Rio de Janeiro. 
de manutenção corretiva, preventiva e preditiva. Posteriormente, são apresentadas as alternativas de docagem existentes, os eventos que podem levar à parada de um navio, o detalhamento das partes do navio e os testes finais de operacionalidade. Por fim, entende-se que a docagem é uma preciosa fonte de conhecimento para o engenheiro de manutenção. Isso ocorre em razão das diversas seções que compõe o navio, cada uma com suas características e particularidades, sendo necessária a atuação de profissionais qualificados em diversas áreas, tais como mecânica, elétrica, eletrônica, hidráulica, entre outras. Conclui-se, portanto, que caso a docagem não seja realizada de forma correta, poderá ocorrer a falha de alguma máquina ou equipamento do navio durante a navegação, levando a perdas não planejadas ou até mesmo a parada do navio, prejudicando a rentabilidade do negócio. Por outro lado, um bom planejamento da docagem irá resultar na operação adequada do navio no mar, ou seja, no aumento da confiabilidade desse sistema e na garantia de sua disponibilidade.

Palavras chave: Engenharia, manutenção, embarcação, docagem.

\section{INTRODUÇÃO}

O processo de manutenção de máquinas e equipamentos tem se mostrado essencial ao longo das últimas décadas. Hoje, há uma preocupação não só relacionada a correção da falha de um sistema, mas também a prevenção de futuras falhas. A manutenção pode ser aplicada em sistemas simples, como por exemplo, em uma máquina independente, e também em sistemas complexos, composto por diversas máquinas e equipamentos que estão interligados entre si, de forma que a falha em uma máquina pode gerar sérios prejuízos a todo o sistema, o que é verificado no procedimento de docagem de embarcações.

No capítulo 2 do presente artigo, item 2.1, é feita uma breve descrição da evolução da manutenção ao longo do tempo e são introduzidos os conceitos de manutenção corretiva, preventiva e preditiva. No item 2.2, é apresentada a docagem, processo de 
manutenção e reparo de embarcações. São analisadas as alternativas de docagem, as causas, os itens em reparo na oficinal naval, e os testes de operacionalidade.

O objetivo central deste trabalho consiste em realizar uma análise a respeito do procedimento de manutenção e reparo de embarcações, indicando as suas principais características e desafios enfrentados durante esse processo.

\section{DESENVOLVIMENTO}

\subsection{ENGENHARIA DE MANUTENÇÃO}

O conceito de manutenção está relacionado não só ao conserto e reparo de alguma coisa, mas também à atividade de preservação, sustentação e conservação de algo em suas características originais, tais como máquinas e equipamentos, patrimônios históricos, entre outros.

De acordo com Xavier (2009), a Engenharia de Manutenção é definida como o conjunto de atividades que viabiliza o aumento da confiabilidade e garante a disponibilidade, dentro do ambiente industrial e de produção. Dessa forma, consiste em desenvolver a manutenibilidade, melhorar padrões e sistemáticas, com o objetivo de deixar de ficar consertando e convivendo com problemas crônicos.

\subsubsection{A EVOLUÇÃO DA MANUTENÇÃO}

Analisando as informações segundo Soeiro, Olivio e Lucato (2017), a evolução da manutenção pode ser dividida em três gerações. Na primeira geração (de 1940 até 1950), as indústrias eram pouco mecanizadas, com máquinas e equipamentos lentos, superdimensionados e de baixa tecnologia. Eram necessários somente serviços de limpeza, lubrificação e reparo após a quebra, não havendo espaço para uma manutenção sistematizada. A segunda geração (de 1950 até 1970), foi marcada pelo aumento da mecanização com plantas industriais mais complexas, necessidade de maior disponibilidade, confiabilidade e produtividade. Dessa forma, surgiu a ideia de que as falhas nos equipamentos poderiam ser evitadas. Já na terceira geração (a 
partir de 1970), houve uma enorme necessidade de garantir a confiabilidade, assim, foram desenvolvidas ferramentas de análise e combate às falhas, com um enfoque empresarial e competitivo.

\subsubsection{MANUTENÇÕES CORRETIVAS, PREVENTIVAS E PREDITIVAS}

A manutenção corretiva consiste no reparo do equipamento somente após a falha. Ou seja, não existe um planejamento prévio, espera-se que as máquinas parem de funcionar, para então executar a correção dos problemas. Geralmente, é o tipo de manutenção que acarreta maiores gastos, sendo indicada somente em alguns tipos de ocasiões, como nos casos onde não é possível prevenir a falha ou quando o custo da manutenção corretiva for baixo.

A manutenção preventiva, é aquela realizada de forma periódica e consiste em tarefas sistemáticas, com intervalos definidos, onde o gestor é capaz de exercer controle sobre o equipamento. Dessa forma, há a troca e reforma de peças antes da ocorrência da falha. Em geral, o custo da manutenção preventiva é superior ao da manutenção corretiva, porém, o resultado é o aumento da disponibilidade do equipamento e a diminuição da ocorrência de falhas.

A manutenção preditiva se utiliza da tecnologia avançada para fazer um monitoramento contínuo das condições mecânicas e elétricas das máquinas, informando o momento certo de parada do equipamento para manutenção, com o objetivo de reduzir as perdas por falhas e quebras. Não substitui integralmente as manutenções corretivas e preventivas, mas visa diminuir a frequência delas.

\subsection{DOCAGEM: MANUTENÇÃO E REPARO DE EMBARCAÇÕES}

O procedimento de docagem consiste em retirar uma embarcação da água e colocála em uma estrutura denominada dique, localizada em um estaleiro, para que se possa realizar processos de manutenção e reparos geralmente de ordem maior, que não podem ser realizados com o barco em operação. A docagem visa garantir que a embarcação está apta a navegar e operar com boas condições de performance e

Disponível em: https://www.nucleodoconhecimento.com.br/engenharia-de-producao/docagem-deembarcacoes 
segurança. Assim, é fundamental para aumentar a vida útil de cada peça, máquina ou equipamento, e consequentemente da embarcação como um todo. Durante a docagem, é possível identificar as deficiências existentes, que passarão pelo processo de manutenção corretiva, assim como as deficiências que possam surgir futuramente, para as quais serão aplicadas a manutenção preventiva. A periodicidade das manutenções e reparos, assim como as exigências legais para se considerar uma embarcação apta a operar, irão variar de forma significativa dependendo do tipo da embarcação.

Figura 1 - Embarcação em Docagem (Dique Flutuante)

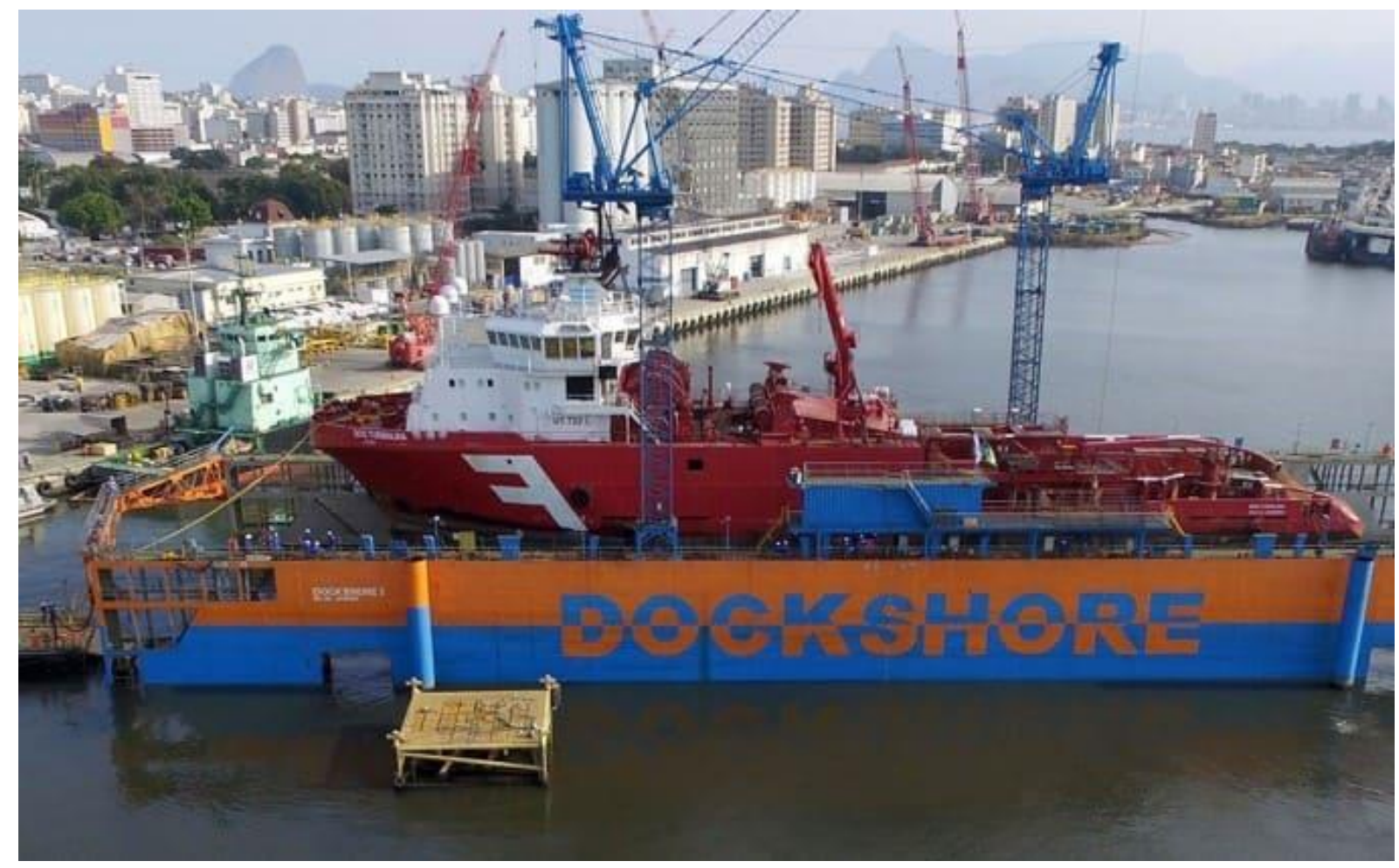

Fonte: Dockshore, 2017

\subsubsection{ALTERNATIVAS DE DOCAGEM}

Para a realização das atividades de manutenção e reparo se faz necessária a escolha do dique mais adequado para o navio em questão. Essa escolha irá depender de

Disponível em: https://www.nucleodoconhecimento.com.br/engenharia-de-producao/docagem-de$\underline{\text { embarcacoes }}$ 
fatores como o orçamento disponível, operação, características e restrições da embarcação. Abaixo os três principais tipos de diques:

a) dique seco: consistem em escavações em terra próxima ao mar, com a construção de paredes e com um porta-batel (porta estanque) que separa a área seca do dique da área do mar. Assim, é formada uma grande bacia, que pode ser alagada com a abertura do porta-batel, permitindo a entrada de embarcações;

b) dique flutuante: composto de uma estrutura móvel capaz de emergir e submergir, com a finalidade de retirar o navio da água;

c) syncrolift (vertical lifts): mecanismo composto por uma plataforma, que, descida na água, suspende verticalmente o navio do mar para o seco. Pode ser equipado com trilhos capazes de mover o navio para dentro do estaleiro.

\subsubsection{CAUSAS DE DOCAGEM}

De acordo com Valladão (2016), há diversas causas que irão resultar na parada de um navio para docagem. Elas podem ser programadas, tais como vistorias obrigatórias ou de rotina, ou inesperadas, a exemplo de acidentes que causam avarias. Lista-se abaixo as causas mais comuns de paradas para docagem:

a) vistorias obrigatórias: são paradas obrigatórias do navio para inspeção e adequação (se necessário), e incluem a renovação de certificados de classe e de certificados estatutários de autoridades marítimas;

b) avarias: caracterizada pelo dano, desgaste ou corrosão que ocorra na estrutura ou no sistema do navio. Além das avarias, as falhas ou suspeitas de falhas nos equipamentos também podem ser motivo para docagem; 
c) reparos de rotina: mesmo sem a ocorrência de avarias ou falhas, pode ser necessária a parada do navio para reparos de rotina, que estão associados à operação normal da embarcação. $O$ ideal é conciliar as datas para reparo de rotina com as datas programadas para a vistoria obrigatória;

d) conversões e modificações: são as maiores modificações nos navios, tais como modificações estruturais, de sistemas ou de função da embarcação, como por exemplo a conversão de navios tanque em FPSOs.

\subsubsection{ITENS EM REPARO DURANTE A DOCAGEM}

Conforme explicado por Vasques (2016), a docagem é um evento complexo, devido a existência de diversos sistemas e áreas distintas com necessidades e características diferentes na embarcação. Dessa forma, é essencial dividir a embarcação em seções para que se possa organizar melhor a manutenção e o reparo. Os problemas técnicos existentes serão os mais variados possíveis, sendo os mais comuns, problemas mecânicos e estruturais, podendo ocorrer também problemas hidráulicos, eletrônicos, pneumáticos, entre outros. Além disso, deve-se atentar para a entrega de materiais, logística de compras, elaboração de documentos e parte contábil e financeira. Todos os itens citados anteriormente estão relacionados entre si e dependentes de prazos e ordens de execução.

A divisão em seções será um facilitador na organização da manutenção, ajudando a destacar de forma particular os problemas e a necessidade de cada um dos setores, e a determinar os responsáveis pela execução dos trabalhos a serem efetuados. Portanto, pode-se dividir o sistema navio nas seguintes partes:

a) casco: avaliação estrutural da embarcação, para garantir o processo de integridade do casco, através da leitura de espessura por ultrassom, e comparação das espessuras de chapas e reforçadores estruturais com os valores originais; tratamento e pintura do casco; manutenções

Disponível em: https://www.nucleodoconhecimento.com.br/engenharia-de-producao/docagem-deembarcacoes 
diversas em acessórios do casco (caixas de mar, válvulas de fundo, hélice e eixo propulsor, leme, anodos, etc.);

b) convés: é onde estão situados o sistema de ancoragem, âncoras e amarras, sistema de carga e descarga, além de equipamentos de salvatagem, segurança e combate a incêndio. O convés é dotado de tubulações, porões, guindastes, entre outros que necessitam de serviços de pintura e medição de espessura;

c) área de carga - porões: costumam sofrer impactos tais como desgastes, deformações, falhas estruturais e ataques químicos pela movimentação da carga. Passam pelo processo de medição de espessura e avaliação da integridade estrutural, além de tratamento e pintura;

d) área de carga - tanques: são divididos em tanques de lastro, de combustível e de água doce. São submetidos à inspeção visual para a análise da integridade estrutural e corrosão;

e) sistema elétrico: composto pelos geradores, quadros elétricos e motores elétricos. Durante a docagem é essencial limpar os componentes do sistema elétrico com produtos químicos específicos;

f) praça de máquinas: composta pelos Motores de Combustão Principais (MCP) e Auxiliares (MCA), além de geradores, caldeiras, bombas, compressores, válvulas, sistema pneumático, sistema de água doce, sistema de água salgada, sistema de combustível e sistema séptico. São checados todos os sistemas e efetuados limpezas, reparos, ajustes e upgrades. Todos os sistemas são dependentes um do outro, assim, falhas que ocorrem em um sistema irão afetar os outros;

g) superestrutura: parte do navio onde reside a tripulação, e comporta o sistema de comando de navegação, as acomodações, além de 
equipamentos para comunicação, segurança e combate a incêndio. São realizados serviços de manutenção na rede elétrica, no sistema de exaustão e nas redes de água e esgoto.

É importante ressaltar que nem todos os procedimentos de manutenção e reparo são realizados exclusivamente durante o processo de docagem. Dependendo da seção trabalhada, das características da falha e da complexidade do reparo, é possível realizá-lo com o navio em operação.

\subsubsection{TESTES DE OPERACIONALIDADE NA EMBARCAÇÃO}

Após a manutenção ou reparo de um equipamento, é necessária a realização de testes de segurança, para garantir que o equipamento está funcionando de forma adequada, sem riscos de acidente e com a eficiência esperada. No caso de um navio após a docagem, isso não é diferente: são efetuados testes de segurança referentes a integridade estrutural, a estanqueidade dos tanques e a funcionalidade de todos os sistemas, garantindo que a embarcação está apta a operar de forma segura.

Dessa forma, ao sair do dique e ser lançado ao mar, ainda na região próxima ao estaleiro, o navio será submetido a uma série de testes. Em relação à estrutura, todas as soldas devem ser aprovadas pelo classificador presente, e no caso de compartimentos estanques, tais como tanques, são realizados testes de estanqueidade. Além disso, todos os outros sistemas são verificados, como os sistemas de operação de carga, elétrico, segurança, salvatagem, etc. Essa etapa de testes de operacionalidade da embarcação após a docagem é de fundamental importância para garantir o funcionamento correto do navio no mar, evitando assim surpresas futuras.

\section{CONCLUSÃO}

No presente artigo foi apresentada a docagem de embarcações e a organização e os procedimentos de manutenção e reparo que são utilizados durante esse processo. Sendo esse um sistema complexo, dotado de diversas seções, cada uma com suas

Disponível em: https://www.nucleodoconhecimento.com.br/engenharia-de-producao/docagem-deembarcacoes 
características e necessidades particulares, se faz necessário um bom planejamento da docagem, com uma equipe de engenheiros experientes, capazes de inspecionar a embarcação de forma minuciosa. Assim, o planejamento da docagem é algo extremamente trabalhoso, que necessita de profissionais qualificados em diferentes áreas, tais como mecânica, elétrica, eletrônica, hidráulica, entre outras.

O bom planejamento da docagem irá resultar na operação adequada do navio no mar, ou seja, a confiabilidade desse sistema será aumentada e a sua disponibilidade será garantida. Caso a docagem não seja feita de forma correta, isso poderá ocasionar na falha de alguma máquina ou equipamento durante a operação, levando a perdas não planejadas ou até mesmo a parada do navio, afetando a rentabilidade do negócio.

Por fim, entende-se que a docagem é uma preciosa fonte de conhecimento para o engenheiro de manutenção, tendo em vista a complexidade e a interligação dos sistemas multidisciplinares que compõe uma embarcação.

\section{REFERÊNCIAS}

DOCKSHORE, 2017. Disponível em: <http://sinaval.org.br/2017/08/dockshore-obtemprioridade-de-r-118-milhoes-do-fmm-para-construcao-de-dique-flutuante>. Acesso em: 16 abr. 2020.

NEVES, Eduardo José Cardoso. Docagem de Embarcações. Rio de Janeiro: UFRJ, 2019. Disponível em: <http://monografias.poli.ufrj.br>. Acesso em: 14 abr. 2020.

QUINTÃO, Gicelle. Docagem. Disponível em: <http://www.projetomemoria.org/2013/08/docagem>. Acesso em: 15 abr. 2020.

SOEIRO, Marcus Vinícius de Abreu; OLIVIO, Amauri; LUCATO, André Vicente Ricco. Gestão da Manutenção. Londrina: Educacional S.A., 2017. 
VALLADÃO, Marcos de Oliveira Dias. Solução de Docagem para Estaleiro de Reparo de Embarcações de Apoio Offshore. Rio de Janeiro: UFRJ, 2016. Disponível em: <http://monografias.poli.ufrj.br>. Acesso em: 14 abr. 2020.

VASQUES, Reinaldo. Procedimentos de Docagem. Rio de Janeiro: UFRJ, 2016. Disponível em: <http://monografias.poli.ufrj.br>. Acesso em: 14 abr. 2020.

XAVIER, Júlio Nascif. Manutenção - Tipos e Tendências. Belo Horizonte: TECEM - Tecnologia Empresarial. Disponível em: <http://claudemiralves.weebly.com/uploads/3/8/6/2/3862918/tendencia.pdf>. Acesso em: 15 abr. 2020.

Enviado: Maio, 2020.

Aprovado: Junho, 2020. 